\title{
Smartphone Use of Effectiveness in Supporting Young Entrepreneurs Business Activity in the Palopo Using Technology Acceptance Model (TAM)
}

\author{
Muhammad Ikbal, Rahmat Solling Hamid \\ STIE Muhammadiyah Palopo, Indonesia \\ rahmadhamid959@yahoo.co.id
}

\begin{abstract}
The development effort involving young entrepreneurs by age relative in Palopo City is now starting to grow and develop. One of the factors that affect the increasingly rapid development of information and communication technology. The development of information and communication technology enables anyone to conduct business without having to incur substantial costs for investment only places and other infrastructure. This study aims to determine the effectiveness of the use of information and communication technology in this case is a smart phone to support the business activities of young entrepreneurs in Palopo. Total sample of 150 respondents. Data analysis was performed using the Partial Least Square (PLS) with 4.0 WarpPLS program. The results of the study results showed that of the five hypotheses which are built in this research there are four hypotheses that can be accepted: (1) Perceived Ease of Use significant effect on Perceived Usefulness; (2) Perceived Ease of Use significant positive effect on User Satisfaction; (3) Perceived Usefulness significant positive effect on Behavioral intention; (4) User Satisfaction significant positive effect on Behavioral Intention. While the hypothesis is not accepted, namely (1) Perceived Ease of Use positive effect was not significant to the User Satisfaction, which in this hypothetical direct influence that has no significant effect. This study also provides empirical support for the theory of TAM in the context of the Smartphone use by young entrepreneurs in the city of Palopo in support of business activities. The benefits and user satisfaction is an important determinant that explains the interest behaves using Smartphone. In addition Smartphone has a user friendly design that allows users to operate the various service features / applications provided on each brand Smartphone. The results of this research study also found information that would have a positive impact on young entrepreneurs perkembagan with age categories were taken from 20 years has begun to grow. This indicates that the motivation, innovation and creativity among young entrepreneurs to continue to try to create jobs independently.
\end{abstract}

Keywords: Perceived Ease of Use, Perceived Usefulness, User Satisfaction, and Behavioral Intention.

\section{Introduction}

Development of business in Indonesia, especially involving employers with a relatively young age quite rapidly now. It is quite influential in increasing the number of young entrepreneurs is a growing number of program provision of venture capital of some banks as well as the rapid development of information and communication technology. The development of information and communication technology enables anyone to conduct business without having to incur substantial costs for investment only places and other infrastructure. Creative ideas and innovative in the world of business continue to emerge, in which the main actors play an important role in the birth of creative ideas are young people who seemed to continue to thirst for inspiration in all areas to maintain the existence of the city as a center for creative industries not only to the local level, Indonesia but also as the main barometer of the creativity of young people in the Southeast Asian region even more broadly Asia. Previous research that has been discussed about the effectiveness of the use of information and communication technology in business activity by using the technology acceptance model (TAM) that was originally developed by Davis (1989) amounts to pretty much starting from the period 1989 to the present. TAM was originally created specifically for modeling the information system user adoption. Davis (1989) explains that the main objective of TAM is to set up a search base effect of external factors on beliefs, attitudes (personalization), and the destination computer users. In the concept of TAM there are two variables key behaviors in adopting sis item information, the user's perception of the benefits (perceived usefulness) and the user's perception of the use of (perceived ease of use). Perceived usefulness is defined as the level at which a person believes that using a particular system can improve its performance and perceived ease of use is defined as the degree to which a person believes that using the 
system is not required any effort. Perceived ease of use also affects the perceived usefulness which may mean that if a person feels the system is easy to use, the system is useful for them.

Youth creativity Palopo town continues to grow of course, inseparable from the role of information and communication technologies are used. Forms of information and communication technology which is often used by young entrepreneurs Palopo town one of them is a Smartphone with various types and brands. Smartphone is no longer an expensive item among young entrepreneur, but already is a staple in running the daily business activities as well as to simply as a means of communication with family and colleagues. Based on this background, this study sought to conduct further study on the role and effectiveness of the use of smart phones in the young entrepreneurs in the town of Palopo, particularly in maintaining the existence and also as a tool to keep the creativity and innovation of its products and services dihasikannya. With reference to the model developed by Davis, the problem in this study is formulated as follows: (1) Are Perceived Ease of Use effect on Perceived Usefulness, (2) Are Perceived Usefulness effect on User Satisfaction, (3) Are Perceived Ease of Use effect on User Satisfaction, (4) Perceived Usefulness effect on Behavioral Intention to Use Smart Phone, (5) What is the effect on the User Satisfaction Behavioral Intention to Use Smart Phone. The purpose of this study was to determine the effectiveness of the use of information and communication technology in this case is a smart phone to support the business activities of young entrepreneurs in Palopo.

\section{Literature Review and Hypothesis}

TAM (Technological Acceptance Model): TAM (Technological Acceptance Model) is the theory of information systems that create a model of how users will receive and use the technology. The Technology Acceptance Model is an information systems theory that models the users' acceptance and utilization of technology. It is very popular models, made through the adaptation of the Theory of Reasoned Action (TRA) "specifically tailored for modeling user acceptance of information systems" Davis et al. (1989) in the Milosevic et al. (2014). Furthermore, according to Milosevic et al. (2014) in a research study that "The models Suggests that when users are presented with a new technology, a number of factors influence Reviews their decision about how and when they will use it. Key factors are stated as perceived usefulness and perceived ease of use ". Model Technology Acceptance Model (TAM) can be presented in figure 1 below:

\section{Figure 1: Technology Acceptance Model (TAM)}

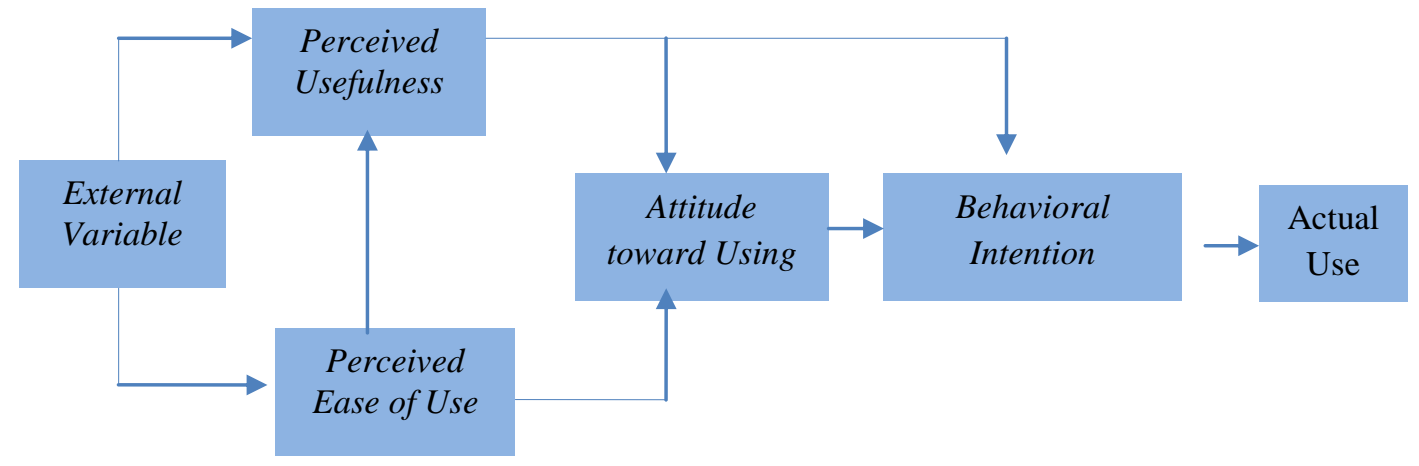

Davis (1989)

Source: Davis (1989) in the Milosevic et al. (2014).

The concept used in this study is a model berketerimaan technology (Technology Acceptance Model TAM). TAM is based on the theory of reasoned action (Theory of Reasoned Action - TRA) developed by Ajzen and Fishbein (1975) in Ni-Luh and I Wayan (2014). In TAM, acceptance of information systems is determined by two key factors, namely perceived usefulness and perceived ease of use. This model has the purpose to explain the key factors of the behavior of users of information technology to the acceptance of the technology adoption such information. The expansion of the concept of TAM is expected to help predict a person's 
attitude and acceptance of the technology and can provide the necessary basic information about the factors that drives the individual's attitude, Lee and Wan (2010). Based on the theoretical foundation of the TAM (Technological Acceptance Model) that TAM basic model consists of six elements. Nevertheless, TAM basic model can be modified in accordance with the objectives or interests of an investigation, Aufar (2009: 32). TAM (Technological Acceptance Model) is the theory of information systems that create a model of how users will receive and use technology. TAM model actually adopted from the model theory of Reasoned Action (TRA) is the theory reasonable measures with the premise that the reactions and one's perception of things, will determine the attitudes and behavior of people (Davis, 1989) in Wiwin and Rusmin (2014). "TAM has proven to be useful theoretical models in helping to understand and explain the acceptance and usage behavior towards technology in information system implementations. It has been tested in many empirical Researches and the tools used with the models have proven to be of quality and to yield statistically reliable results "(Chen et al., 2011, p. 202).

Had many previous studies that have examined the effectiveness of the use of information and communications technology by using technology acceptance model (TAM). Among Wiwin and Rusmin (2014), where the model has been used in research Technology Acceptance Model (TAM) as a framework or model of research with the purpose of receipt of an information system by the user. Saleh and Drew (2014) in their study using the technology acceptance model (TAM) show the positive influence of perceived ease of use on perceived usefulness. Then the findings made by Azhari and Intan-Sari (2008: 1) that the Perceived Ease of Use (perception of ease of use) as the degree to which the user believes that the technology / systems that can be used easily and free of problems. The test results Mao and Palvia (2006) shows the influence of perceived ease of use on perceived usefulness. Azhari and Intan-Sari (2008: 1) that the Perceived Usefulness (Perceived Benefits) is defined as the degree to which the user believes that by using technology / the system will improve the performance of their work.

Then Azhari and Intan-Sari (2008: 1) that the Perceived Ease of Use (perception of ease of use) as the degree to which the user believes that the technology / systems that can be used easily and free of problems. Straub and Brenner (1994) in Wilson (2013) in which the results of the study that the perceived ease of use is insignificant in America, Switzerland and Japan. The results are consistent with research conducted Adams, Nelson and Todd (1992) and Davis (1989) in Wilson (2013). The lack of such significance, according to experts due to an indirect result of the perception of the perceived benefits. Saleh and Drew (2014) also produced findings which Perceived Usefulness positive effect on Intention to use. Aufar (2009) that the level of use of a computer technology on a person can be predicted from the attitude of attention to the technology, for example, my wish to add peripherals support, motivation to continue to use, as well as a desire to motivate users other.

Aufar (2009) argued that the level of use of a computer technology on a person can be predicted from the attitude of attention to the technology, for example supporting my wish to add peripherals, motivation to continue to use, as well as a desire to motivate other users. Based on the theoretical foundation of the TAM (Technological Acceptance Model) that TAM basic model consists of six elements. Nevertheless, TAM basic model can be modified in accordance with the objectives or interests of an investigation, Aufar (2009: 32 ). Thus the conceptual framework in this study the researchers add user satisfaction factor into the model TAM described by the research model as follows:

Figure 2: Concept Framework Research

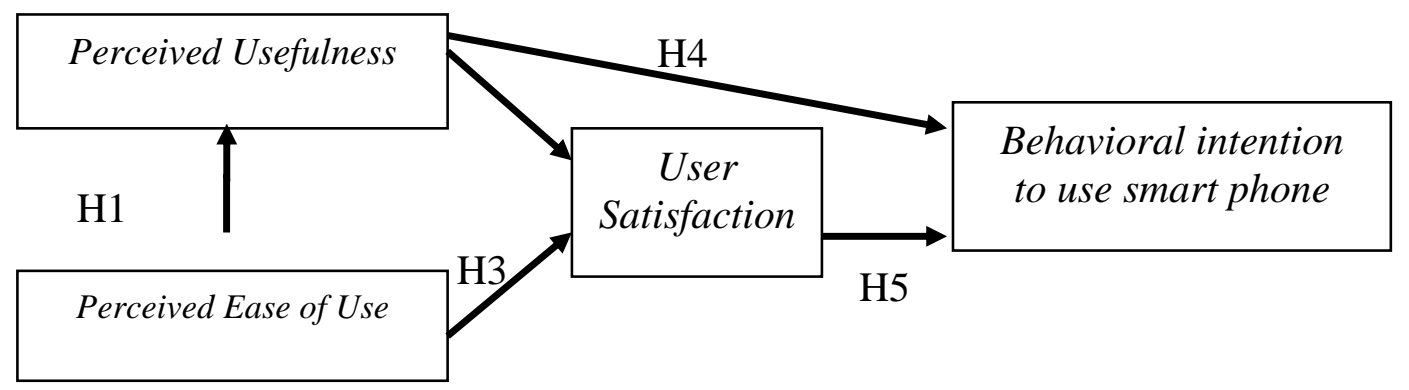


Based on the results of previous research related to the study, the researchers developed a research hypothesis as follows:

H1: Perceived Ease of Use effect on Perceived Usefulness

H2: Perceived Usefulness effect on User Satisfaction

H3: Perceived Ease of Use affect the User Satisfaction

H4: Perceived Usefulness effect on Behavioral Intention to Use Smart Phone

H5: User Satisfaction effect on Behavioral Intention touse Smart Phone.

\section{Methodology}

Types of research: This type of research is an explanatory research (explanatory research), which tries to explain the causal relationship (causal) between the exogenous variables (Perceived Usefulness and Perceived Ease of Use) of the endogenous variables (User Satisfaction and Behavioral Intention to Use Smart Phone).

Data Collection Methods and Measurement Scale: Data collection method used in this study is a survey method. Survey methods made directly to the respondents intended to use the study questionnaire. Questionnaires were distributed to about 150 potential respondents who meet the criteria as a young entrepreneur. Data obtained from the prospective respondent Department of Cooperatives and Micro, Small and Medium Enterprises (MSME) and the Indonesian Young Entrepreneurs Association (HIPMI) Palopo. In addition, data obtained based on the initial data collection aimed at entrepreneurial communities scattered in several universities in Palopo town as well as the identification results through social media facebook and twitter. Of the total of 150 questionnaires have been distributed in whole kemabali and the completed according to the needs of research. Data four variables are ordinal data Likert scale with a score of 1 to 5 .

Data Analysis Methods: The data analysis method used is Descriptive Analysis and Partial Least Square (PLS). Partial Least Square (PLS) is a multivariate analysis technique that aims to examine the relationship between constructs predictions by looking at whether there is a connection or influence between these constructs southern Hengky (2013: 14). Interest PLS is to test the theory of the weak and weak data, such as small sample size or there is a problem normality of the data, predicting the effect of exogenous variables on endogenous variables, and explains the theoretical relationship between the two variables. The steps that must be done in PLS include, Ghozali (2012):

a. The design of structural models (inner model) to explain the relationship between the latent variables with each other latent variables;

b. The design of the measurement model (outer model) that describes the relationship between the latent variables with a reflective indicator variable in this study;

c. Construction drafting path diagram based on two models, namely the structural model and the measurement model;

d. Conversion path diagram into a structural equation model (the relationship between latent variables studied) and the measurement model (indicator variable relationship with the latent variable);

e. The estimation of the parameters in the PLS (reflective models) conducted by way of $a$ path estimate (estimated path);

f. Evaluation of Goodness of Fit by way of testing the suitability of the model, namely the outer model (Convergent validity, Discriminant validity, and Composite reliability)and inner model ( $R$-Square or Adjusted R-Square, Effect Size (f 2), Variance accounted For (VAF ),;

g. Hypothesis testing is done with a Stable resampling methods and test statistics used was t test.

\section{Research Finding}

Analysis Descriptive statistics (Characteristics of Respondents): From the recapitulation of the respondent profile data in this study shows that the gender of respondents was dominated by male respondents - male as many as 90 people (60\%). The age of respondents was dominated by the age group of 21 years to 30 years as many as 75 people (50\%). The dominant type of business of the respondents is general trading (trading) as many as 80 people (53.33\%). For the amount of total monthly turnover is dominated by a group turnover of 5 million down as many as 60 people (40\%) followed by the group with the 
total amount of turnover per month ie 6 million to 10 million as many as 55 people (36.67\%), this condition showed that most respondents in the study was classified into the category of small and medium enterprises, although it is possible they will experience growth / development to become major employers when viewed from the side of the age of the majority of the relatively young or less than 30 years, so it's still wide open to develop the business.

Then an interesting thing that is a percentage value of the main consumer areas of origin in which the ratio between the City and the Outer City Palopo Palopo (Local) is not much different that each - each for Palopo many as 79 people (52.67\%) and for outside Palopo as many as 71 people (47.33\%). This shows that young entrepreneurs in Palopo is not entirely dependent on the market in Palopo City and surrounding areas alone, but have to be accepted by local markets that exist in the Outer City Palopo. For Smartphone types used by the respondent is a type of Samsung Android as many as 67 people (44.67\%). Furthermore, to feature Smartphone used by respondents is the kind of phone features as many as 62 people (41.33), followed by SMS as many as 30 people (20\%), and fuel (Black Barry Messenger) as many as 28 people (18.67), then social media (facebook, twitter, etc.) as many as 20 people $(13.33 \%)$ and the least used features that MMS as many as 10 people (6.67\%). This shows that all respondents greatly benefit from technology Smartphone in its business activities the day - day, well used to maintain contact and communication with colleagues, as well as consumers, but also with some of the features offered in the Smart Phone for example, social media will be very helpful to use to promote the latest product information and services from businesses, media to inform the offer - an attractive offer to consumers.

\section{Evaluation Measurement Model (Outer Model) convergent Validity}

Value Loading Factor: Convergent validity of the test results with the value parameter loading factor for each - each indicator has a value above $(>0.60)$ except for a few indicators that still has a value below than 0.60 . To construct Perceived Ease of Use consisting of three indicators, namely PEOU1 = 0.834; PEOU2 = 0.626; and PEOU3 $=0.537$, which of these three indicators is only one indicator that they have a value below 0.60 which is an indicator PEOU3 $=0.537$, so this indicator in the droop of the model. Then to construct Perceived Usefulness of three indicators, namely PU1 $=0.722$; PU2 $=0.697$; Pu3 $=0.596$, which of these three indicators is only one indicator that they have a value below 0.60 which is an indicator pu3 $=0.537$, so this indicator in the droop of the model. Proceed with the User Satisfaction construct consisting of four indicators namely US1 $=0.687$; US2 $=0.721$; US3 $=0.557$; and US4 $=0.690$, which of these four indicators is only one indicator that they have a value below 0.60 which is an indicator US3 $=0.537$, so this indicator in the droop of the model. Behavioral Intention to construct consisting of three indicators, namely BI1 = 0.895; Bi2 = 0.737; and $\mathrm{BI} 3=(-0.093)$, which of these three indicators is only one indicator that they have a value below 0.60 which is an indicator BI3 $=(-0.093)$, so this indicator in the droop of the model. After testing a second stage in which all indicators of the construct in the droop of the model, then the values obtained new loading factor loading factor values obtained for each - each construct that is already above 0.60. It can be concluded that the indicators forming the construct of Perceived Ease of Use, Perceived Usefulness, User Satisfaction, and Behavioral Intention categorized valid.

Value Average Variance Extracted (AVE): Convergent validity of the test results with parameter values Average Variance Extracted (AVE) obtained that value Average Variance Extracted (AVE) for each - each construct is Perceived Ease of Use $=0.601$; Perceived Usefulness $=0.608 ;$ User Satisfaction $=$ 0.521 and Behavioral Intention $=0.706$ own values above 0.50, meaning that the construct four categorized valid. Thus, to test convergent validity consisting of cross loading the parameter value, and Average Variance Extracted (AVE) terkategori valid.

Discriminant Validity: Convergent validity of the test results with the square root of a value parameter (AVE) the result that the value of the square root of the AVE for each construct is greater than the value of the correlation between the constructs in the model that each - each worth Perceived Ease of Use= 0.775; Perceived Usefulness $=0.780 ;$ User Satisfaction $=0.721$ and Behavioral Intention $=0.840$.

Composite Reliability: The reliability of the test results with parameter values obtained Composite Composite Reliability Reliability for each - each construct is Perceived Ease of Use $=0.748$; Perceived Usefulness $=$ 
0.756; User Satisfaction $=0,765$ and Behavioral Intention $=0.827$ own values above of 0.70 , meaning that the construct four categorized reliable. Thus, to test convergent validity with the parameter value of loading factor and Average Variance Extracted (AVE), discriminant validity test parameters AVE square roots and correlation between latent constructs and reliability tests with the parameters Composite Reliability valid and reliable.

Structural Model (Inner Model): Adapaun test results or inner structural model of the model in this study can be presented in the following figure:

Figure 3: Result Analysis of Structural Model (Inner Model)

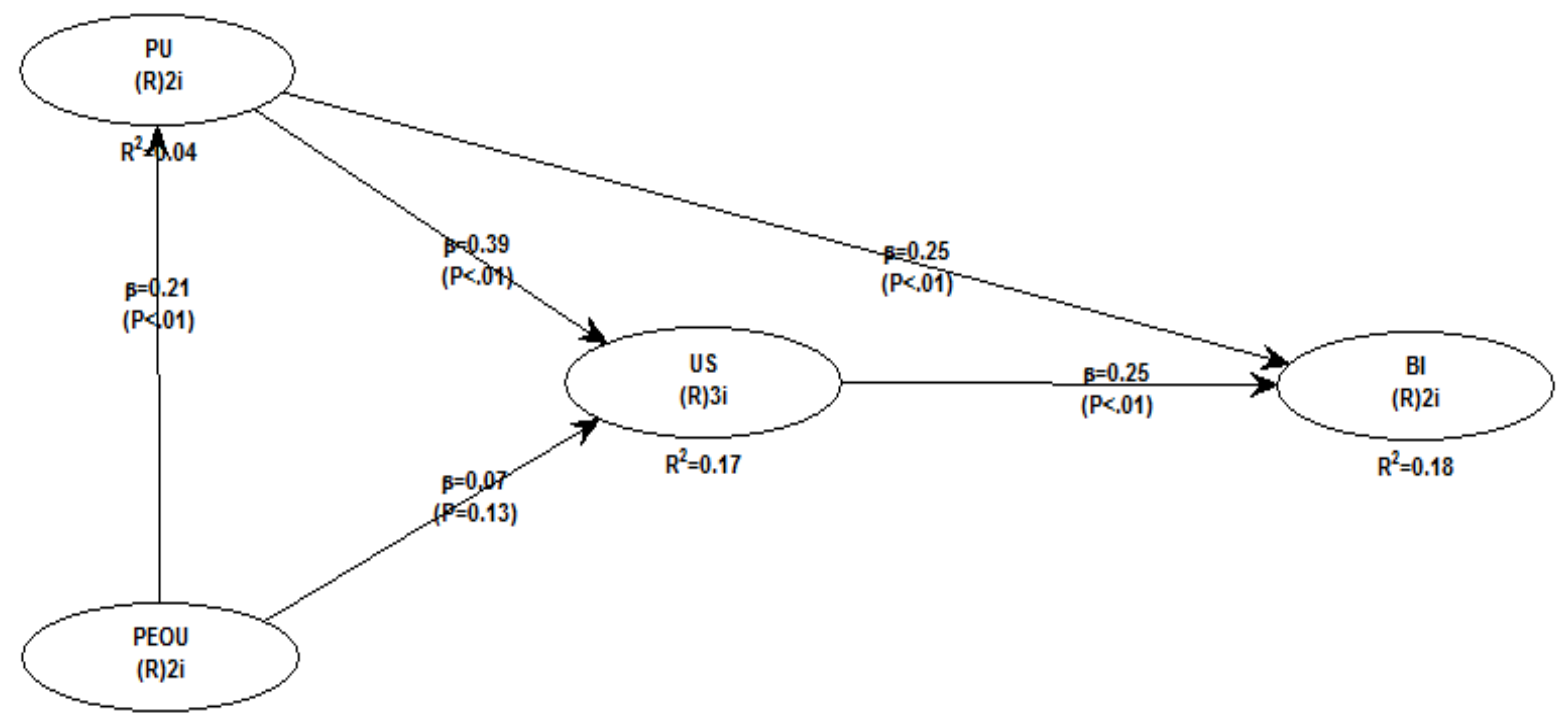

Source: Data processed, 2015

Results and Discussion Research Hypothesis Testing: Results of testing the hypothesis in this study can be explained in detail as follows:

Effect of Perceived Ease of Use on Perceived Usefulness: Perceived Ease of Use direct impact positively and significantly to Perceived Usefulness, meaning that with increasing Perceived Ease of Use, followed by an increase in Perceived Usefulness. This means that the respondents have a positive perception of the use of smart phone technology when viewed from the Perceived Ease of Use and Perceived Usefulness. This means that the respondents consider that each of these features and applications owned by Smart Phone they use either in the form of design, responsibility / responsiveness (high speed) perceived well as having the benefit of the business activities of young entrepreneurs in Palopo. Thus we can conclude that Hypothesis 1 stated that Perceived Ease of Use positive effect on Perceived Usefulness acceptable. The acceptance of this hypothesis is consistent with the findings made by Saleh and Drew (2014) where the Perceived Ease of Use significant effect on Perceived Usefulness. Then, the findings made by Azhari and Intan-Sari (2008: 1) that the Perceived Ease of use (perception of ease of use) as the degree to which the user believes that the technology / systems that can be used easily and free of problems. Mao and Palvia (2006) inform us that the results of the study conducted show the influence of perceived ease of use on perceived usefulness. Jahroni (2015) also yield information that Perceived Ease of Use positive effect on Perceived Usefulness.

Effect of Perceived Usefulness of the User Satisfaction: perceived Usefulness directly affect positively and significantly to the User Satisfaction means that with increasing Perceived Usefulness then followed by an increase in User Satisfaction. This means that the respondents have a positive perception of the use of smart phone technology when viewed from the Perceived Usefulness and User Satisfaction. This means that the respondents considered that the level of accuracy, the technology Smart Phone owned by the young entrepreneurs in the City of Palopo is considered important because it can affect the timeliness of the business conducted at each connection and Smart Phone technology can provide ease and motivate the young 
entrepreneurs in Palopo to always develop the creativity and innovation of each activity / business idea. Then the respondents perceive the good in other words they feel comfortable with the tool / application features internet connection and other support software available in the Smart Phone, which the respondents considered that the Smart Phone has able to act as a media / tools to facilitate the learning process innovation and creativity in the development of business ideas on the run. Thus we can conclude that Hypothesis 2 stated that Perceived Usefulness positive effect on User Satisfaction acceptable. The acceptance of this hypothesis is consistent with the findings made by Azhari and Intan-Sari (2008: 1) that the Perceived Usefulness (Perceived Benefits) is defined as the degree to which the user believes that by using the technology / systems will improve their performance in work. Jahroni (2015) also yield information that Perceived Usefulness positive effect on Satisfaction.

Effect of Direct and Indirect Perceived Ease of Use to the User Satisfaction: Perceived Ease of Use no significant positive effect directly to the User Satisfaction, meaning that with increasing Perceived Ease of Use then it is not followed by an increase in User Satisfaction. This means that the majority of respondents considered that although the Smart Phone offers a wide range of features and facilities that are easy to use by the young entrepreneurs in Palopo, but respondents in this case young entrepreneurs in Palopo assume that they have to adjust to the level of expediency Smart Phone to business activities / efforts, Perceived Ease of Use positive and significant impact indirectly on User Satisfaction with Perceived Usefulness, Perceived Usefulness means constructs could play a role in mediating between Perceived Ease of Use to the User Satisfaction. Where respondents believe that Smart Phone users by the young entrepreneurs in Palopo fixed forward in terms of the benefits of using a Smart Phone to support business activities / business development. Along with the development of a Smart Phone which is quite rapid with various brands especially in the city of Palopo, community of young entrepreneurs in the city of Palopo is also very concerned about the Smart Phone that they use to support them in developing business / business. Here Perceived Usefulness good role in mediating between Perceived Ease of Use to the User Satisfaction.

It can be concluded that the third hypothesis which states that the Perceived Ease of Use positive effect on User Satisfaction unacceptable. Rejection of the hypothesis of this study are consistent with some previous research conducted by Straub and Brenner (1994) in Wilson (2013) in which the results of the study that the perceived ease of use is not significant in the United States, Switzerland and Japan. The results are consistent with research conducted Adams, Nelson and Todd (1992) and Davis (1989) in Wilson (2013). The lack of such significance, according to experts due to an indirect result of the perception of the perceived benefits. Rejection of the hypothesis of the study was not in line with the views expressed by Azhari and Intan-Sari (2008: 1) that the Perceived Ease of Use (perception of ease of use) as the degree to which the user believes that the technology / systems that can be used easily and freely of the problem.

Effect of Direct and Indirect Perceived Usefulness of the Behavioral Intention: Perceived Usefulness significant positive effect directly on Behavioral Intention, meaning that with the increase in Perceived Usefulness it will increase Behavioral Intention. This means that the respondents considered that the benefits obtained from the use of technology Smart Phone felt very positive influence on the development of enterprises / businesses they run. Where young entrepreneurs in Palopo tend to stick to behave to continue to use a technology that is Smart Phone in supporting the development of enterprises / businesses they run. Perceived Usefulness significant positive effect indirectly to Behavioral Intention through User Satisfaction, meaning that the construct of User Satisfaction able to play well in mediating between the construct of Perceived Usefulness of the Behavioral Intention. Where the respondents thought that the benefits they have gained from the use of technology Smart Phone in support of business development / bisninya turns perceived satisfied by the young entrepreneurs in Palopo, it is drawn from the pattern of their habits in bringing Smart Phone every routine activity especially business activity.

It can be concluded that the hypothesis 4 which states that Perceived Usefulness positive effect on Behavioral Intention acceptable. The acceptance of the research hypothesis is consistent with the findings made by Saleh and Drew (2014) where the Perceived Usefulness positive effect on Intention to Use. Then hasi is also supported by the findings of Aufar (2009) that the level of use of a computer technology to someone can be predicted from the attitude of attention to the technology, for example, my wish to add peripherals support, 
motivation to continue to use, as well as a desire to motivate other users. This behavior tendency is influenced by the perception of usefulness and attitude toward usage.

Effect of User Satisfaction Against Behavioral Intention: User Satisfaction positive and significant impact directly on Behavioral Intention, meaning that with increasing User Satisfaction followed by increased Behavioral Intention. This means that the tendency of the behavior of young entrepreneurs in Palopo City that has been considered that the technology Smart Phone can support business activities / business they develop. Most assume that the Smart Phone that is inside equipped with a variety of features, applications internet connection can obtain a certain satisfaction, especially in transactions, promotion of products or goods resulting from the business or the business developed, it has been very helpful in terms of time efficiency, for example. It can be concluded that the hypothesis which states that 5 User Satisfaction positive effect on Behavioral Intention acceptable. The acceptance of this study are consistent with the hypothesis made by Aufar (2009) that the level of a person's computer technology can be predicted from the attitude of attention to the technology, for example, my wish to add peripherals support, motivation to continue to use, as well as a desire to motivate other users. This behavior tendency is influenced by the perception of usefulness and attitude toward usage.

\section{Conclusion and Recommendations}

Based on the subject matter, the purpose of research and discussion, it can be argued conclusion of the study showed that of the five hypotheses which are built in this research there are four hypotheses that can be accepted, namely (1) Perceived Ease of Use significant effect on Perceived Usefulness; (2) Perceived Ease of Use significant positive effect on User Satisfaction; (3) Perceived Use fullness significant positive effect on Behavioral intention; (4) User Satisfaction significant positive effect on Behavioral Intention.While the hypothesis is not accepted, namely (1) Perceived Ease of Use positive effect was not significant to the User Satisfaction, which on this hypothesis direct effect which has no significant effect. The findings of this study provide important contributions to the study of consumer behavior, especially in the phenomenon of the use of technology Smartphone. Specifically, the study found an important role Smartphone in support of any activity or business activities of young entrepreneurs in the city of Palopo. This study also provides empirical support for the theory of TAM in the context of the use of Smartphone by young entrepreneurs in the city of Palopo in support of business activities. The benefits and user satisfaction is an important determinant that explains the interest behaves using Smartphone. In addition Smartphone has a design that is user friendly which allows users to operate the various service features / applications provided on each brand Smartphone.

However, the problem lies in the internet connection is still not evenly distributed to all service providers in Indonesia, it is also considered researchers to spread the questionnaire using a computer-based questionnaire and paper-based questionnaire, so that researchers spread the questionnaire manually to each respondent, Another interesting thing that the respondents in choosing Smartphone still pay attention to brand image, and community means that the respondent does not only focus on the benefits provided to the Smart Phone, but how much of fellow community of young entrepreneurs who use a Smart Phone. The results of this research study also found information that would have a positive impact on young entrepreneurs perkembagan with age categories were taken from 20 years has begun to grow. This indicates that the motivation, innovation and creativity among young entrepreneurs to continue to try to create jobs independently. Here it takes the role of government to create a comfortable climate for entrepreneurs, especially for new entrepreneurs. Governments also need to create rules that facilitate entrepreneurs to develop their business.

\section{References}

Aufar, I. (2009). Use of the Framework Technology Acceptance Model in Doing Rating Factors influencing the adoption of e-Government Pemko field. Essay. Faculty of Engineering. University of Northern Sumatra. Field.

Azhari, R. \& Intan-Sari, H. Z. (2008). Models User Acceptance. Journal of the Faculty of Computer Science. University of Indonesia. 
Chen, S. C., Li, S. H. \& Li, C. Y. (2011). Recent Related Research in Technology Acceptance Model: A Literature Review. Australian Journal of Business and Management Research, 1 (9), 124-127.

Davis, F. D. (1989). Perceived Usefulness, Perceived Ease of Use, and User Acceptance of Information Technology. MIS Quarterly, 13(3), 319-340.

Ghozali, I. (2012). Partial Least Squares: Concepts, Techniques, and Applications using the program SmartPLS 3.0 for Empirical Research. Universitas Diponegoro: Semarang.

Hengky, L. (2013). Structural Equation Model: Theory and Implementation AMOS 21.0. Alfabeta: Bandung.

Jahroni. (2015). Use of Technology In of Sales Online System To Improve Satisfaction At the Micro, Small and Medium Industry Bags and Suitcases (INTAKO) Sidoarjo. Journal: Ebis, 7(1).

Milosevic, M., Zecirovic, E. \& Radojka, K. (2014). Technology Acceptance Models and Learning Management System: Case Study. The Fifth International Conference on e-Learning (eLearning-2014) September 22 to 23, 2014. Belgrade: Serbia.

Mao, E. \& Prashant, P. (2006). Testing an Extended Model of IT Acceptance in the Chinese Cultural Context. The Database for Advances in Information Systems, 37(6).

Ni-Luh, N. S. D. \& I-Wayan, S. (2014). Analysis of the Technology Acceptance Model (TAM) of the Use of Information Systems at the Nusa Dua Beach Hotel \& SPA. E-Journal of Accounting Universitas Udayana, 6(1), 167-184. ISSN: 2302-8556

Lee, P. \& Wan, C. B. G. (2010). Including Subjective Norm and Technology Trust in the Tekhnology Acceptance Model: A Case of E-Ticketing in China. The Data Base for Advances in Information Systems, 41(2), 4051.

Saleh, A. \& Drew, S. (2014). Using the Technology Acceptance Model in Understanding Academics' Behavioral Intention to Use Learning Mangement Systems. (IJACSA) International Journal of Advanced Computer Science and Applications, 5(1), 2014.

Wilson, B. (2013). The Ability of Human Resources in Supporting Regional Autonomy (A Study at Employees in Sitaro Regency). IOSR Journal of Business and Management (IOSR-JBM), 15(2), 37-44.

Wiwin, A. \& Rusmin, S. (2014). Approach Technology Acceptance Model (TAM) To Identify Internet Utilization of Small and Medium Businesses South Sumatra. National Seminar on Information and Communication Technology Applied (Semantics 2014): Semarang. ISBN: 979-26-0276-3. 